\title{
Memória e narrativa: Walter Benjamin, nostalgia e movência
}

\author{
Felipe Grüne Ewald*
}

Resumo: O presente artigo parte do ensaio "O Narrador", de Walter Benjamin, em busca de uma reflexão acerca de memória e narrativa. Um de seus intentos é a atualização das discussões levantadas pelo autor alemão, dado o afastamento temporal em que nos encontramos. O risco de desaparecimento do narrador, antevisto diante do caos da guerra e do fascismo, é refutado, preferindo-se optar por uma perspectiva dinâmica da tradição. Para realizar a discussão, são abordados dois exemplos de narradores contemporâneos, que poderão diferir do modelo imaginado por Benjamin, mas sem deixar de exibir uma originalidade. Mesmo com seu sentimento nostálgico, podemos vislumbrar no autor o reconhecimento ao dinamismo da faculdade de narrar e da elaboração da memória, que são hoje redimensionadas pelo avanço técnico.

Palavras-chave: memória; narrativa; Walter Benjamin; oralidade.

\begin{abstract}
The present article sets its starting point on the essay "The Storyteller" by Walter Benjamin, in order to undertake a reflection on memory and narrative. One of its attempts is the upgrade of the discussions raised by the German author, given the distance in time where we find ourselves. The risk of disappearance of the storyteller, foreseen before the chaos of war and fascism, is rejected over a dynamic view of tradition. To make the discussion we have considered two examples of contemporary storytellers, which may differ from the model imagined by Benjamin, but can still show some originality. Despite his nostalgic feeling, it's still possible to acknowledge that the German thinker recognizes the dynamic power of storytelling and of the development of memory, which are currently scaled by the advance of technology and rationality.
\end{abstract}

Keywords: memory; narrative; Walter Benjamin; orality.

\begin{abstract}
Ah! indiscreta! ah! ignorantona! Mas é isso mesmo que nos faz senhores da terra, é esse poder de restaurar o passado, para tocar a instabilidade das nossas impressões e a vaidade dos nossos afetos.
\end{abstract}

Machado de Assis

Walter Benjamin publica o ensaio "O Narrador - considerações sobre a obra de Nikolai Leskov", em 1936, ainda sob os efeitos da guerra de trincheiras e já sob o fantasma do ascendente totalitarismo na Europa. A datação deste contexto parece importante para compreender o tom que marca o citado ensaio, assim como sua obra em geral. Ele vive um tempo de devastação e desesperança, direcionando seu olhar e suas esperanças para o passado e incorrendo no risco de idealizá-lo.

O texto tem como tema inicial a análise da obra de Nikolai Leskov, ampliando-se a partir daí. Segundo a visão já apontada anteriormente, Leskov seria exemplo de um passado a

\footnotetext{
* Mestrando do PPGLET - UFRGS. Integra o Projeto Corpo e voz em performance nas narrativas orais urbanas, coordenado pela Professora Ana Lúcia Liberato Tettamanzy. E-mail: felipe.ewald@gmail.com.
} 
ser valorizado, para Benjamin em vias de devastação, sendo prova disto a distância verificada por ele entre os dados do seu tempo e o autor russo, enquanto exemplo notável de um verdadeiro narrador.

A extinção da arte de narrar seria patente diante do silêncio dos soldados retornados da guerra. Apagar-se-ia assim a faculdade de intercambiar experiências através do contato humano, que é a fonte das narrativas. Diante do ambiente de desesperança, é natural que estas questões viessem à tona. Mas, como exporei mais adiante, sob a perspectiva do tempo decorrido e do afastamento, podemos vislumbrar novas possibilidades.

Benjamin participa da tradição filosófica alemã, e especialmente frankfurtiana, e apresenta uma visão nostálgica do mundo, narrando a história cultural como um processo de desencantamento, de degradação de uma totalidade (ALEXANDER, 2006). Apesar de ainda se verificarem discursos nostálgicos, existem algumas linhas de pensamento que seguem uma perspectiva de reencantamento. Carlos Nogueira aponta que:

\begin{abstract}
nas novas formas e funcionalidades assumidas pela literatura oral, [incorporada à massificação tecnológica e informativa,] intervém um refinamento que se apropria da essência da beleza desses objetos literários que não esgotaram a sua força estético-comunicativa. Seríamos muito ingénuos e crédulos se pensássemos que a literatura oral poderia ou deveria continuar a ser uma reprodução exacta das formas cristalizadas nas muitas coletâneas (escritas, sonoras ou audiovisuais) de que dispomos. (NOGUEIRA, 2007, p.22)
\end{abstract}

Esta seria uma perspectiva engessante da realidade, bastante presente entre os românticos, que buscaria a 'salvação' das narrativas. O que se está aqui ressaltando é a dimensão dinâmica do mundo - que Paul Zumthor (2005) nomeia movência. Diante do processo de aceleração capitalista, Antonio Candido (2002), assim como ZUMTHOR (2000), reconhece uma redefinição da comunicação oral propiciada pelos desenvolvimentos da técnica. Ao invés de devastar, esta provoca um redimensionamento dos espaços da voz e da narrativa na vida cotidiana.

Para dar conta da fluidez e da indeterminação deste processo, podemos buscar inspiração na Teoria da Prática, quebrando o modelo paralisante de cultura, pensando em termos de práticas culturais. Com o auxílio dos Estudos de Performance e do conceito de liminoid de TURNER (1987), que propõe um processo individual e alternativo na constituição de formas culturais, chegamos a mais uma perspectiva de reencantamento. Pelas narrativas orais, ainda podemos contar e recontar nossas estórias e mantermos consciência de nós mesmos (HUGHES, 1998) e, creio, de nossa comunidade. Desta forma, parece ser possível reconquistar aquilo que Benjamin receava já ter-se perdido. As narrativas parecem ter um caminho - provavelmente não idêntico ao exposto por Benjamin - na troca de experiências e 
conseqüente construção da realidade; no redimensionamento da tradição.

Estas narrativas podem se apresentar de diferentes formas, não apenas na oralidade viva, mas sempre remetendo a ela. Benjamin expõe a impressão de que o romance provoca o apagamento da narrativa, vinculando-se ao livro e sua fixidez, ainda que, por outro lado, não tenha problemas em afirmar anteriormente que a narrativa escrita persegue a narrativa oral, ou seja, não vê impedimentos em fixar o oral na escrita. Entendo então que a questão para ele não está na escrita, mas, como ele coloca, no fato de o romance ser distinto da tradição oral, não procedendo desta, nem a alimentando. No entanto, esta afirmação me parece precipitada, pois nela verifica-se que Benjamin retorna à sua vontade de pureza e idealização, enquanto, na verdade, podemos perceber um cenário em que romance, escrita e oralidade se vêem imbricados.

A pesquisa em história oral de Janaína Amado (1995) é um exemplo que atesta esta situação. Com o intuito de reconstituir um evento do passado, a Revolta do Formoso, no Estado de Goiás, ela busca diferentes relatos em uma comunidade e depara-se com Fernandes, um informante que narra episódios, misturando acontecimentos e personagens, alguns reais, outros fictícios, embaralhando tempos e espaços. À medida que a trama se desenrola, a pesquisadora se dá conta de que se tratava de uma recriação sertaneja do Dom Quixote de la Mancha, de Cervantes.

Cultura erudita (Dom Quixote) e cultura popular (tradições goianas) associaram-se, assim, influenciando-se mutuamente e promovendo uma circularidade de culturas [...]. Associaram-se, também, escrita e oralidade: um texto escrito alimentou, durante séculos, uma tradição mista, escrita e oral, em Goiás (AMADO, 1995, p.130).

Fernandes, o informante de Janaína Amado, realiza um processo próximo ao descrito por Scholes e Kellogg (1977) no desenvolvimento do conceito de topos. Segundo os autores, a narrativa oral é uma repetição criadora a partir de fórmulas, que se realiza, tendo por base imagens tradicionais, os topoi. O narrador goiano, por sua vez, combinou esquemas de tradições arraigadas na coletividade com acontecimentos verídicos presenciados por ele ou relatados por outros, reelaborando de maneira original sua narrativa.

Talvez a questão de Benjamin em relação ao romance possa ser entendida mais especificamente em função da interiorização que ele provoca, mantendo-se numa esfera individual e afastado dos conselhos e do senso prático das narrativas, os quais para Benjamin carregam a sabedoria, que, por sua vez, constituiria o lado épico da verdade. Mas, na continuação deste trajeto, ele parece imiscuir o romance com a imprensa, que carrega uma nova forma de comunicação: a informação, a qual passou a influenciar decisivamente as 
formas épicas, devastando a narrativa e ameaçando o próprio romance. Neste ponto parece haver um embaraço entre a ameaça latente no romance e na imprensa, dando uma impressão de que uma seria, de certa forma, extensão do outro. Mas de maneira alguma alcanço conceber os romances de Hermilo Borba Filho (1968) ou de Luis Cardoso (2003) como fortemente explicativos. Nem tampouco verifico explicação e plausibilidade estrita nas narrativas orais urbanas que vivencio na pesquisa que desenvolvo no bairro Restinga, em Porto Alegre. Nesta atividade, proponho aliar o trabalho de campo aos estudos literários, e analiso performances de narrativas orais urbanas, enquanto manifestações dinâmicas e espontâneas da poética no contexto da vida cotidiana. Enfoco as possibilidades e conseqüências resultantes da ação de tomar estas narrativas da voz como objeto literário, mapeando marcas, recursos e elementos que concorrem para o agenciamento de ficcionalidade e caráter poético.

O trabalho transcorre em encontros semanais, promovidos por um morador específico, de apelido Beleza, que reúne alguns membros da comunidade, a fim de construir um material sobre a história e a identidade de seu bairro, elaborando uma ferramenta pedagógica que estimule e informe os jovens de sua história e cultura. Beleza e seus vizinhos confeccionam sua rede de memórias, narrando, num discurso épico, eventos de suas vidas que carregam exemplos de aplicação prática para o presente ou mesmo visando ao futuro. Se trazem um cunho de aconselhamento, estas narrativas portam uma necessidade de encantamento, ocasionam o engendramento de uma poética, uma "poética da vida social" (LIMA, 2003). Vejamos - e, com algum esforço, escutemos - um curto episódio direto da voz do Beleza:

Aí eles queriam, quiseram me botar pra rua. Aí, como eu tinha sempre essa coisa de ser sempre conversador fiado, né, então aí os caras não. Uma vez os caras quiseram me botar pra rua. Os caras vieram de comitiva até a minha casa, eu morava aqui já na Restinga. Me avisaram: "não vai lá que os caras querem te botar pra rua. Tu dá um jeito, te some, faz qualquer coisa. Tu cinco dias agora tu não pode aparecer lá. Aí, daqui uns cinco dias tu nos telefona que nós vamos conversar contigo". Tá, cinco dias (????) as pessoas que eu conhecia, né, eles. Não apareci cinco dias. Aí cheguei, depois dos cinco dias lá (????) "nós vamos ter que arrumar, tu vai ter que entrar pro sindicato. Eles querem te botar pra rua”. Já arrumaram até cópia da minha demissão: "olha, tá aqui ó, só não te botaram pra rua ainda porque não te acharam pra tu assinar este negócio, senão já tinham te botado. Então, o seguinte, nós vamos, tu vai ter que arrumar, tu vai ter que dar uma de louco agora, tu vai ter que entrar no INSS, pra tu aguardar um tempo, pra tu entrar no sindicato. Tu não pode sair", né, então isso fez com que. A gente acabou desenvolvendo um monte de coisa, aprender coisas que daí eu realmente tive que dar uma de louco mesmo, né, tinha que crescer cabelo, barba, não tomava mais banho, comecei a caminhar na rua, tinha que ter testemunha, né, tinha que ter testemunha pra isso - ALEX: falava com os cachorros - é falava com os, é, via bicho, barulho no telhado, ia no médico lá e aí minha mulher soube se, se prestou pra isso. Até gravar, ela gravou coisas pra levar lá pro médico e mostrar pro médico o que tava acontecendo comigo, né. Aí eu sei que depois de todas essas andanças, aí o cara mandou fazer uma biometria num outro médico, que não era do INSS, porque o INSS não tinha naquela época - ANA: não tinha perito? - não tinha perito. Aí eu fui fazer num consultório particular. Aí cheguei lá, o médico falava e eu não parava nunca, eu parecia um, eu andava e saía pra lá e pra cá, digo “ó, não vou porque aqui tem gente que tá me 
perseguindo aqui" e o médico abria uns olhão assim pra mim. Aí o médico pegou e disse assim: "não, vou dar (????)", lacrou o envelope e mandou lá pro INSS. Aí cheguei lá no INSS, o médico olhando pra mim e eu olhando pra ele, né, ficamos ali só, sabe como é que é, esses psiquiatras têm isso, né, eles gostam muito de ficar observando, né, são tão loucos quanto os loucos, né, na verdade. Aí o cara ficou me olhando e eu olhando pra ele. E ficamos ali, acho que uma hora e pouco, ele olhando pra mim e eu olhando pra ele. Aí, daqui a pouco, a minha mulher entrou na sala e disse: "vem cá, o que que tá acontecendo?" - MARAGATO: vocês estão apaixonados?, um olhando pro outro - aí diz a minha mulher: "que que tá acontecendo? Vocês não falam, tão olhando um pra cara do outro, já passou uma hora e tanto, o que tá". "Não, mas eu tô observando ele". Aí, a minha mulher: "tá, e aí, o que que tu tá fazendo olhando pra ele?". "Ah, eu tô olhando prum louco aí, que tá me olhando, tá olhando prum outro louco". Aí, então tá, aí o médico pegou, abriu o envelope, falou: "realmente não sei o que, o senhor tá, vou dar seis meses pro senhor ficar aqui, daqui não sei quanto tempo o senhor volta pra fazer acompanhamento", e pronto. Aí, deu os seis meses, fui lá, entrei no, me inscreveram no tal de sindicato, daí a chapa que eu tinha me inscrito foi eleita, aquele negócio tudo. (Transcrição bruta de registro audiovisual obtido em 18 de agosto de 2006)

Esta ilustração provoca sobre os limites de lembrança, imaginação, poética, história, realidade, ficção. Em último caso, ela aponta para uma harmonia possível. Posso ir à Restinga e escutar a sabedoria prática e épica e, ao chegar em casa, ler um romance de Machado de Assis - para ficar num exemplo bastante canônico - confrontando as informações e aferindo os conhecimentos transmitidos. Segue perdurando a alternativa da escuta. Para escutar, é preciso que alguns silenciem, um silêncio observador e atento, que joga para o outro a oportunidade de falar e ser ouvido. Beleza mantém a exclusividade da criação da narrativa, mas o faz diante de uma platéia que intervém e responde aos estímulos desta. A platéia, por sua vez, mesmo mantendo a oportunidade de intervir, precisa se colocar na posição de escuta para garantir seu papel de audiência que constitui a totalidade da performance. O silêncio que assusta Benjamin (1985) também pode vir a ser ativo e criativo, também tem o seu lugar na concretização das narrativas. O contar é dinâmico, e sua força se restitui a cada vez que se retoma a contação.

Quando tiramos o foco da exclusividade do texto escrito e levamos nossos ouvidos à periferia, onde o falatório vociferante da crítica tradicional é menos intenso, por falta de interesse da mesma por este segmento sócio-cultural, podemos arejar nosso pensamento crítico, com novos horizontes para pensar as possibilidades narrativas. Em áreas periféricas, pelos menores vícios e ruídos acadêmicos, é mais facilmente averiguada a transmissão da sabedoria, podendo o passado ser retomado no fio da memória, mas sempre com o presente em perspectiva, mantendo a complexidade integrativa do evento humano da narrativa.

Refiro-me à discussão retomada por Bauman (1986), a partir das propostas de Bakhtin e Roman Jakobson, em relação à necessidade de considerar conjuntamente o Evento Narrado - o episódio do passado, a memória bruta - e o Evento Narrativo - a ativação da memória, através da mediação da imaginação poética. Pelo exercício da performance, o evento narrado 
é reencenado, revivido, atualizado no evento narrativo. Para Janaína Amado:

A memória torna as experiências inteligíveis, conferindo-lhes significados. Ao trazer o passado até o presente, recria o passado, ao mesmo tempo em que o projeta no futuro; graças a essa capacidade da memória de transitar livremente entre os diversos tempos, é que o passado se torna verdadeiramente passado, e o futuro, futuro. (AMADO, 1995, p.132)

A visão integrativa da narrativa está presente em Benjamin (1985), quando este afirma que o narrador, nas histórias que conta, recorre ao acervo de experiências de vida, tanto as suas como as experiências relatadas por outros. Ao narrar, ele as transforma em produto sólido e único, tornando-as experiências daqueles que estão ouvindo. Assim ocorre a transmissão de conselhos e conhecimentos, o que afirma o papel constitutivo do discurso na vida social, em uma concepção de "literatura como prática social” (BAUMAN, 1986, p.3).

Desejo compreender as narrativas do Beleza através deste enquadre. Ao enfatizar a conexão entre narrar e lembrar, ele expõe a ligação intrínseca que há entre memória, narrativa oral e ação social. A história é construída socialmente, através de uma interação, nos momentos de espacialização, por meio da voz, do corpo e de inscrições. É isto que relata ao comentar sobre um caderno que mantém - uma espécie de diário de campo -, o qual cumpre uma necessidade de dilatação, de se jogar para fora, de se expandir. Neste caderno, há o entrelaçamento dos mais diversos elementos: são adesivos, figuras, colagens, definições de verbetes, desenhos de próprio punho, folhas soltas, documentos, poemas próprios e de outros autores, dados extraídos de pesquisas em jornais ou na internet, agendas de contatos, folhas avulsas de anotações, relatos de reuniões e oficinas, brochuras, convites, programações, projetos e assim por diante.

Eu tenho o hábito de guardar as coisas que a gente passava, pra poder me identificar com as pessoas na rua ou poder conversar... toda vez que tu passava por uma pessoa que era morador ou era teu vizinho, tu conversava com ele lá e não ia deixar nada pra ele e ele não se lembrava, então tu tinha que se lembrar [...] e assim era a coisa... eu sempre fui... tava no ônibus, tava escrevendo um negócio e assim vai... aqui tem o nome, ó, do movimento centopéia: foi um movimento que teve no orçamento participativo, em 98, se não me engano, onde nós reunimos escola, comunidade, casa de batuque, tudo que tinha, que queria participar de um movimento que tinha, que era chamado de movimento centopéia, que era um movimento pela educação, que nós entendíamos que a educa--não construir prédio, né, mas a educação da comunidade, das pessoas, dos indivíduos, numa causa maior, então era isso, então sempre foi isso. [...] O que era interessante, o que achava que tinha que estar, guardava aqui, pra ter registrado e, quando encontrar alguém, mostrar pras pessoas. [...] O valor pra mim é o conteúdo, não é o arranjo do negócio. [...] então, deu vontade de escrever, eu escrevi isto daqui, sei lá, um dia eu ia lembrar, né. [...] tinha essas, eu hoje perdi um pouco essas manias de fazer, mas eu tinha, eu organizava aquela lista de contatos com pessoas, eu tinha o contato com pessoas mais..., eu mantenho uma lista aqui dentro de contatos, essa aqui, ó, que são pessoas que realmente eu podia conversar com elas, porque tem, tu tem contato, mas às vezes não dá nem pra conversar porque é perda de tempo muitas vezes, ou vai só pra cumprir, cumprir agenda, ah tá vou dizer lá pro cara que tem coisas, porque é uma obrigação só, mas não, não que aquilo vá render alguma coisa; então eu tinha esse hábito de separar minha agenda, minha agenda tinha alguém que eu fazia e ficava dentro do meu caderno, aquelas pessoas com que eu podia conversar, eu sei que elas iam me 
ouvir, pra alguma coisa elas iam me ouvir, podia não dar lá grandes resultados, mas iam ouvir. (Transcrição bruta de registro audiovisual obtido em 22 de novembro de 2007)

Este trecho ilustra bem a capacidade do Beleza de reunir escrita e oralidade, perpassando âmbitos individuais e coletivos, na constituição da memória, através da narrativa, alcançando a transmissão de conhecimentos práticos. Ao narrar as inscrições fixadas em seu caderno, ele completa e atualiza a memória em uma interação, que é atravessada pela concretude e espacialização da voz e do corpo:

A narração, em seu aspecto sensível, não é de modo algum o produto exclusivo da voz. Na verdadeira narração, a mão intervém decisivamente, com seus gestos [...] que sustentam de cem maneiras o fluxo do que é dito. (BENJAMIN, 1985, p.220-1)

Janaína Amado comenta que o gesto traz esta força, pois carrega consigo a potência da memória e da tradição:

No relato de Fernandes, a "memória herdada" das antigas gerações de Goiás pinçou para o
presente da entrevista o "homem de ontem", o Quixote, transmutado das tradições ibéricas para
as tradições goianas. Fernandes o fez com tal força e nitidez, que denunciou a presença de
habitus, esquemas inconscientes de percepção, representação e ação tão incorporados à sua
pessoa, que já faziam parte dele inscritos em seu corpo, mente, fala, gestos, riso. [Ele recorreu]
a códigos mentais, psicológicos e corporais inscritos no mais íntimo do seu ser. (AMADO,
1995, p.133)

Nem na escrita, nem na oralidade - repetindo: diante do conforto do distanciamento temporal em que me encontro - vejo esta devastação alertada por Benjamin. Ainda que para ele a questão não se dê exatamente assim, já que não está preocupado em preservar a narrativa oral longe da escrita, tanto que disserta sobre a obra escrita de Leskov. Mesmo assim, ele fala no desaparecimento da comunidade dos ouvintes e do dom de ouvir, marcando o caráter imprescindível da oralidade para a narrativa. Sendo o contar a arte de contar de novo, a narrativa se perde se a história não for conservada. Sobre a escuta e a conservação, penso que hoje podemos pensar em uma comunidade que se trasladou para os novos meios de comunicação, que se fazem entre a escrita e a voz. Também houve uma dilatação dos sentidos, a audição dividindo o espaço com a visão, mais presente atualmente. Também no meio visual ou audiovisual a narrativa passou a tomar forma. A rede narrativa que se tece agora se dá também na dimensão virtual.

De qualquer forma, pode-se pensar que Benjamin, ainda que sob o peso da nostalgia, conferia certa dinâmica à narrativa, o que é reforçado pela sensação de vigor, até o desenvolvimento da imprensa, das formas épicas de que a narrativa faz parte. Isto é enfatizado pela vontade de conservar - e recontar - o que foi narrado. Aí se coloca a noção de reminiscência, ou mais especificamente a memória, tida por Benjamin como a mais épica das 
faculdades. De uma origem comum na epopéia, o romance toma a forma perpetuadora da memória, centrando-se no nível individual, enquanto que a narrativa corresponde às formas efêmeras de reminiscências, num nível coletivo. Esta constatação aponta para o fato de que as narrativas - orais ou escritas -, por serem compartilhadas e efêmeras e por se sujeitarem ao desaparecimento com a morte, podem se desenvolver livremente, não estando presas a amarras fixas - não sendo a escrita um impedimento para que assim se dê.

\section{Referências}

ALEXANDER, Jeffrey et al. Introduction: symbolic action in theory and practice: the cultural pragmatics of symbolic action. In: . Social Performance: symbolic action, cultural pragmatics and ritual. Cambridge University Press, 2006.

AMADO, Janaína. O Grande Mentiroso: tradição, veracidade e imaginação em história oral. História. São Paulo, n.14, 1995, p. 125-136.

BAUMAN, Richard. Story, Performance and Event: contextual studies of oral narrative. Cambridge University Press, 1986.

BENJAMIN, Walter. O Narrador - considerações sobre a obra de Nikolai Leskov. In: Magia e técnica, arte e política. São Paulo: Brasiliense, 1985.

BORBA Filho, Hermilo. O Cavalo da Noite. Rio de Janeiro: Civilização Brasileira, 1968.

CANDIDO, Antonio. A literatura e a formação do homem. In: Textos de Intervenção. São Paulo: Duas Cidades/Editora 34, 2002.

CARDOSO, Luis. A última morte do Coronel Santiago. Lisboa: Dom Quixote, 2003.

HUGHES-Freeland, Felicia (org.). Ritual, Performance, Media. London: Routledge, 1998.

LIMA, Nei Clara. Narrativas Orais: uma poética da vida social. Brasília: UnB, 2003.

NOGUEIRA, Carlos. As literaturas orais e marginalizadas. Organon. Porto Alegre, n.42, janjun, 2007, p.17-31.

SCHOLES, Robert/ KELLOGG, Robert. A natureza da narrativa. São Paulo: McGraw-Hill, 1977.

TURNER, Victor. The Anthropology of Performance. NY: PAJ, 1987, p. 72-98.

ZUMTHOR, Paul. Escritura e Nomadismo. São Paulo: Ateliê Editorial, 2005. . Performance, Recepção, Leitura. São Paulo: Educ, 2000. 